\title{
A clinical diagnosis of oral leukoplakia; A guide for dentists
}

\author{
Vinicius C. Carrard ${ }^{1}$, Isaäc van der Waal ${ }^{2}$ \\ ${ }^{1}$ Federal University of Rio Grande do Sul, School of Dentistry, Porte Alegre, Rio Grande do Sul, Brazil \\ ${ }^{2}$ VU medical center/ ACTA, Dept. of Oral and Maxillofacial Surgery/Pathology, Amsterdam, the Netherlands
}

Correspondence:

VU medical center/ ACTA,

dept. of Oral and Maxillofacial Surgery/Pathology

P.O. Box 7057, 1007 MB, Amsterdam, The Netherlands

i.vanderwaal@hotmail.com

Received: 22/11/2017 Accepted: 06/12/2017

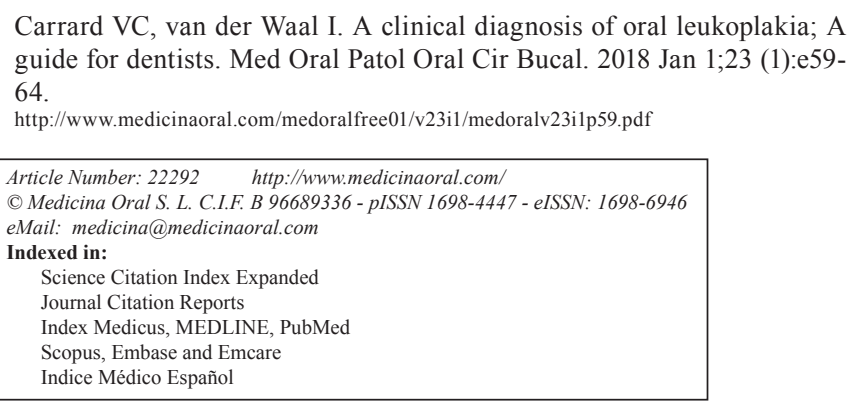

\begin{abstract}
Background: In view of the many white or predominantly white lesions of the oral mucosa it is a challenge for dentists to clinically identify a leukoplakia, being a potentially (pre)malignant lesion.

Material and Methods: Based on the available literature and experience of the authors the parameters of a clinical diagnosis of oral leukoplakia have been studied.

Results: A guide has been presented that should help dentists to establish a clinical diagnosis of leukoplakia as accurate as possible.

Conclusions: Probably in most parts of the world dentists will need the help of a specialist for confirmation or exclusion of the clinical diagnosis of oral leukoplakia and for further management of the patient, including patient information.
\end{abstract}

Key words: Oral diseases, oral leukoplakia.

\section{Introduction}

Oral leukoplakia, being a predominantly white change of the oral mucosa, is the most common potentially (pre)malignant lesion. It is a relatively rare disease with an estimated prevalence of less than $1 \%$. Men and women are more or less equally affected. Oral leukoplakia rarely occurs in the first two decades of life and is much more common in tobacco users than in non-tobacco us- ers. Leukoplakia may occur everywhere in the oral cavity and is often asymptomatic otherwise. The clinical diagnosis is primarily based on visual inspection and manual palpation. There are no other useful diagnostic aids for the clinical diagnosis.

The histopathological findings in leukoplakia range from hyperkeratosis without epithelial dysplasia to various degrees of epithelial dysplasia and even carcinoma 
in situ, frank squamous cell carcinoma and verrucous carcinoma.

The annual risk of malignant transformation of leukoplakia, if not malignant already at the first visit, is approximately $2 \%-3 \%$. There are many, statistically somewhat useful, predictive factors of malignant transformation, such as the seize of the lesion, the clinical subtype, the oral subsite, and the presence or absence of epithelial dysplasia as assessed by histopathological examination, but these can not reliably be used in the individual patient. This also applies to numerous molecular markers that have been reported as predictive markers of malignant transformation.

Spontaneous regression of leukoplakia is exceedingly rare. Surgical and non-surgical treatments have not been shown to be effective in preventing possible future malignant transformation (1).

It is a challenge for the general dentist to be able to timely identify a leukoplakia. The most recent definition, formulated at a World Health Organization supported meeting, reads: "A white plaque of questionable risk having excluded (other) known diseases or disorders that carry no increased risk for cancer" (2). For use by clinicians this definition may be modified into : "A predominantly white, non-wipable lesion of the oral mucosa having excluded clinically, histopathologically or by the use of other diagnostic aids other, well-defined predominantly white lesions". In fact, a diagnosis of leukoplakia is one by exclusion of a large number of well-defined common and also uncommon lesions and disorders that may occur in the oral mucosa. A dentist-general practitioner can not be supposed to be familiar with all such lesions and disorders. The present text is intended to serve as a guide for use in the daily practise.

\section{A clinical diagnosis of leukoplakia}

A clinical diagnosis or differential diagnosis of a mucosal lesion is the result of a number of parameters. The importance of each parameter varies according to the type of lesion. The parameters and their relevance with regard to the establishment of a clinical diagnosis of leukoplakia have been listed in table 1 .

Traditionally, leukoplakias are clinically subdivided in a homogeneous and a non-homogeneous variant. In homogeneous leukoplakia the lesion is uniformly white and the surface is flat or slightly wrinkled. In non-homogeneous leukoplakia there is a mixed white-and-red color ("erythroleukoplakia"); the surface may be flat, speckled or nodular. A separate variant of non-homogeneous leukoplakia is the wartlike, verrucous type. In case of a widespread presentation and depending on other criteria such as worsening along time, this type is referred to as proliferative verrucous leukoplakia. Nonhomogeneous leukoplakias carry, statistically, a higher risk of malignant transformation.
A list of leukoplakialike, well-defined predominantly white lesions and their main diagnostic criteria is depicted in table 2,2 continue. This table may be helpful as a checklist in distinguishing such entities from leukoplakia.

The benign white oral mucosal lesions that may be encountered in genodermatoses should not be difficult to diagnose by the dentist, provided the patients have, indeed, disclosed their medical history. This partly also applies to the diagnosis of hairy leukoplakia although there are cases in which the patient is unaware of the underlying HIV infection or immunosuppressive state for other reasons. Another challenge is the diagnosis of white oral lesions as manifestation of the second stage of syphilis. Here, too, the patient may be unaware of the relevance of lifestyle aspects or may be reluctant to disclose these to the dentist. In such instances, a biopsy or another diagnostic aid, particularly serology, may be required.

In some of the listed entities it is questionable whether or not to consider them as a well-defined entity and not as leukoplakia. This particularly applies to "epithelial peeling" (3) and glassblower's white patch; (4) alveolar ridge keratosis (5) and frictional keratosis of the buccal gingiva are other examples (6). Little is known about the possible potentially (pre)malignant character of Sanguinaria-associated keratosis and, therefore, it is actually unknown whether it is justified to separate this lesion from the category of leukoplakia (7). Yet another subject of debate is the Cinnamon-induced contact stomatitis (8).

In case of a possible etiologic factor, such as tobacco use or the presence of an amalgam restoration in close contact with the lesion, the dentist may await the result of the elimination of such factor for no longer than a somewhat arbitrarily chosen period of three months, provided the patient is asymptomatic otherwise. In the presence of symptoms a biopsy should be taken first. In case of a provisional diagnosis of cinnamon-induced lesions or Sanguinaria-associated keratosis it may be difficult to prove the causitive role of such agents.

In the absence of possible etiologic factors or lack of response to the elimination of such factors, referral to a specialist is recommended, both for assessment of the final diagnosis, the further managment of the patient and the provision of adequate patient information.

Probably the most common diagnostic challenge is the distinction between leukoplakia and non-reticular lichen planus and lichenoid lesions from. An example is shown in figure 1. Such distinction is of importance for the management of the patient, which partly relates to the issue of potential (pre)malignancy of leukoplakia and partly to the issue of treatment in case of symptoms, particularly when the use of topical steroids is considered. In such cases a biopsy may be helpful, but even then there may remain cases that can not be clearly 
Table 1: Parameters and their relevance with regard to the process of establishing a clinical diagnosis of oral leukoplakia.

\begin{tabular}{|c|c|}
\hline Parameter & Relevance with regard to a clinical diagnosis of leukoplakia \\
\hline Age & Leukoplakia rarely occurs in the first two decades of life. \\
\hline Gender & Not relevant. \\
\hline Ethnic background & Not relevant, except for a diagnosis of leukodema that is mainly seen in dark skinned people. \\
\hline Medical history & $\begin{array}{l}\text { The medical history is of importance for the diagnosis of several leukoplakialike diseases, such as } \\
\text { the oral manifestations of genodermatoses, syphilis and HIV-infection. }\end{array}$ \\
\hline Profession & $\begin{array}{l}\text { Leukoplakialike lesions may occur in glassblowers; no other professions are of relevance with } \\
\text { regard to a diagnosis of leukoplakia. }\end{array}$ \\
\hline $\begin{array}{l}\text { Tobacco habits of any } \\
\text { type }\end{array}$ & $\begin{array}{l}\text { Leukoplakia is much more common in tobacco users; therefore, this parameter does have some } \\
\text { relevance. }\end{array}$ \\
\hline Symptoms & Most leukoplakias are asymptomatic otherwise, but however pain or itching may occur. \\
\hline Onset of the disease & Most, if not all, leukoplakias arise slowly, probably in a matter of several months or years. \\
\hline Course of the disease & Leukoplakia runs as a stable disease, not showing remissions and exacerbations. \\
\hline \multicolumn{2}{|l|}{ Morphology } \\
\hline Seize & $\begin{array}{l}\text { In previous definitions a minimum diameter of } 0.5 \mathrm{~cm} \text { was required in the definition of leukopla- } \\
\text { kia; at present, this requirement has been deleted. Seize is not relevant with regard to a clinical } \\
\text { diagnosis of leukoplakia. }\end{array}$ \\
\hline Color & $\begin{array}{l}\text { The color of leukoplakia may vary from homogeneous white to a mixed white-and-red appearance } \\
\text { and is a sine qua non for a diagnosis of leukoplakia. }\end{array}$ \\
\hline Texture & $\begin{array}{l}\text { The texture of leukoplakia may vary from smooth, wrinkled to wartlike (verrucous). } \\
\text { Thin, homogeneous leukoplakia should not show induration at palpation; in thick, verrucous leu- } \\
\text { koplakias, the presence of induration at palpation may be difficult to assess. } \\
\text { Ulceration is not a normal finding in leukoplakia and may be indicative of malignancy. }\end{array}$ \\
\hline $\begin{array}{l}\text { Delineation; well-de- } \\
\text { lineated versus poorly } \\
\text { delineated }\end{array}$ & Is not a relevant parameter. \\
\hline $\begin{array}{l}\text { Solitary versus } \\
\text { multiplicity }\end{array}$ & This parameter is not of much relevance. \\
\hline Oral subsite & Leukoplakia may occur at any oral subsite; therefore, subsite is not relevant \\
\hline
\end{tabular}

diagnosed as either leukoplakia or lichen planus or lichenoid lesion.

As a general rule each leukoplakia should be biopsied irrespective of the presence or absence of symptoms, the clinical subtype (homogeneous or non-homogeneous), the seize and the oral subsite. In extensive leukoplakias the taking of multiple biopsies ("mapping") may be considered. Probably in most parts of the world dentists are not trained to perform incisional or excisional biopsies; therefore, referral to a specialist for such procedure is advised.

The treatment policy, particularly in leukoplakias that are otherwise asymptomatic, is an issue of debate in view of the questionable effectiveness of whatever type of surgical or non-surgical treatment (1).

\section{Discussion}

The present definition of leukoplakia has been worded in a negative way by excluding well-defined predomi- nantly white lesions. Therefore, the accuracy of the clinicians' diagnosis very much depends on their diagnostic capabilities. The use of artificial intelligence may become of great help in the near future to support the dentist in obtaining a correct clinical diagnosis of leukoplakia, similar as has been demonstrated in the clinical diagnosis of melanoma of the skin by the use of dermascopic pictures (9). Incorporated in smartphones artificial intelligence might then become a valuable instrument for use by dentists in the diagnostic process of predominantly white lesion of the oral mucosa.

The various terminologies that are being used in relation to the many predominantly white lesions of the oral mucosa, as shown in table II, are somewhat confusing, particularly at the level of the dentist-general practitioner. For instance, hairy leukoplakia is clearly a misnomer since 1) it is a well-defined entity, 2) it is not a potential (pre)malignant lesion, and 3) the lesion is not always "hairy" clinically. The category of so-called keratotic 
Table 2: Well-defined, predominantly white lesions or diseases that should be excluded from a clinical diagnosis of oral leukoplakia.

\begin{tabular}{|c|c|}
\hline Lesion or disease & Main diagnostic criteria \\
\hline Actinic cheilitis & $\begin{array}{l}\text { In actinic cheilitis of the lower lip associated leukoplakialike changes may } \\
\text { occur, sometimes even blurring the typical clinical presentation of actinic } \\
\text { cheilitis. }\end{array}$ \\
\hline $\begin{array}{l}\text { Aspirin burn (including other types } \\
\text { of chemical burns) }\end{array}$ & $\begin{array}{l}\text { History of prolonged application of aspirin tablets or other chemical agents; no } \\
\text { other distinguishing clinical diagnostic criteria. }\end{array}$ \\
\hline $\begin{array}{l}\text { Candidiasis, hyperplastic } \\
\text { pseudomembranous }\end{array}$ & $\begin{array}{l}\text { Somewhat questionable entity; some refer to this lesion as candida-associated } \\
\text { leukoplakia. Mainly located in the commissures and the dorsum and the lateral } \\
\text { borders of the tongue. Some use the results of antifungal treatment for } \\
\text { establishing the diagnosis. Otherwise clinically indistinguishable from } \\
\text { leukoplakia. } \\
\text { Can be easily wiped off. }\end{array}$ \\
\hline $\begin{array}{l}\text { Cinnamon-induced contact } \\
\text { stomatitis }\end{array}$ & $\begin{array}{l}\text { Identification of the frequent use of chewing gums and also of some toothpastes } \\
\text { or other products that contain a high concentrate of cinnamon; rapid onset. No } \\
\text { distinguishing clinical aspects. Usually accompanied by a burning or painful } \\
\text { sensation. }\end{array}$ \\
\hline $\begin{array}{l}\text { Epithelial peeling (Shedding oral } \\
\text { mucosa) }\end{array}$ & $\begin{array}{l}\text { Can be easily wiped off; apparently caused by certain toothpastes } \\
\text { Has been rarely reported. }\end{array}$ \\
\hline $\begin{array}{l}\text { Genodermatoses with benign oral } \\
\text { leukoplakialike changes of the oral } \\
\text { mucosa }\end{array}$ & \\
\hline Darier-White disease & $\begin{array}{l}\text { Simultaneous presence of skin and nail lesions; no distinguishing clinical } \\
\text { criteria. }\end{array}$ \\
\hline Dyskeratosis congenita & $\begin{array}{l}\text { Hereditary disease presenting with cutaneous hyperpigmentation already in the } \\
\text { first decade; oral leukoplakic lesions may develop later in life and do not have } \\
\text { distinguishing clinical aspects. } \\
\text { Histopathology is not diagnostic. }\end{array}$ \\
\hline $\begin{array}{l}\text { Intraepithelial dyskeratosis, } \\
\text { hereditary benign }\end{array}$ & $\begin{array}{l}\text { Extremely rare genodermatosis; presents early in life. Affects the oral and } \\
\text { conjunctival mucosa. } \\
\text { The oral lesions mimic those of white sponge nevus but do not have distinct } \\
\text { distinguishing clinical aspects with regard to leukoplakia. }\end{array}$ \\
\hline Pachyonychia congenita & $\begin{array}{l}\text { Rare genodermatosis characterized by skin involvement and nail changes early } \\
\text { in life } \\
\text { The oral manifestation consists mainly of verrucous, morsicatiolike changes at } \\
\text { the borders of the tongue. No distinct distinguishing aspects. }\end{array}$ \\
\hline White sponge nevus & $\begin{array}{l}\text { Young age; often family history. Always bilateral presentation of somewhat } \\
\text { verrucous white mucosal changes. No distinct distinguishing aspects. }\end{array}$ \\
\hline Geographic tongue & $\begin{array}{l}\text { Almost always easy to recognize by its clinical presentation. Ectopic } \\
\text { geographic tongue (also called geographic stomatitis) may occasionally difficult } \\
\text { to recognize as such. }\end{array}$ \\
\hline Glassblower's white patch & $\begin{array}{l}\text { May occur in glassblowers. No distinguishing aspects. Has been scarcely } \\
\text { reported. }\end{array}$ \\
\hline Hairy leukoplakia & $\begin{array}{l}\text { More or less limited to HIV infected patients but may also occur in patients } \\
\text { who are immunocompromised due to other causes. Almost exclusively } \\
\text { occurring bilateral on the borders of the tongue. Clinical aspect is not } \\
\text { diagnostic. }\end{array}$ \\
\hline $\begin{array}{l}\text { Keratotic lesions (include reversed } \\
\text { smoking keratosis, alveolar ridge } \\
\text { keratosis, frictional keratosis, } \\
\text { sanguinaria-associated keratosis, } \\
\text { tobacco pouch keratosis and } \\
\text { keratosis of unknown significance) }\end{array}$ & $\begin{array}{l}\text { Different etiologies and various clinical presentations without distinct clinical } \\
\text { aspects. } \\
\text { Reversed smoking keratosis and tobacco pouch keratosis have malignant } \\
\text { potential. } \\
\text { It is questionable whether it is justified to exclude alveolar ridge keratosis and } \\
\text { frictional keratosis of the buccal gingiva from the category of leukoplakia. } \\
\text { Sanguinaria-associated keratosis is another somewhat questionable entity. Is } \\
\text { mainly located in the mucobuccal fold in the anterior maxilla. }\end{array}$ \\
\hline
\end{tabular}


Table 2 continue: Well-defined, predominantly white lesions or diseases that should be excluded from a clinical diagnosis of oral leukoplakia.

\begin{tabular}{|c|c|}
\hline $\begin{array}{l}\text { Lesion caused by prolonged, direct } \\
\text { anatomic contact of the oral mucosa } \\
\text { with an amalgam restoration or other } \\
\text { types of dental restoration; often } \\
\text { listed as a lichenoid lesion }\end{array}$ & $\begin{array}{l}\text { No distinguishing clinical aspects. Disappearance of the lesion within an } \\
\text { arbitrarily chosen period of 2-3 months after removal of the restoration; the } \\
\text { taking of a pretreatment biopsy is particularly recommended in case of } \\
\text { symptoms in order to exclude dysplastic or malignant changes } \\
\text { In case of persistence after replacement of the dental restoration the diagnosis } \\
\text { leukoplakia or lichenoid lesion- depending on the clinical presentation- applies }\end{array}$ \\
\hline Leukodema & $\begin{array}{l}\text { Clinical diagnosis of a veil-like aspect of the buccal mucosa, bilaterally; tends } \\
\text { to disappear when stretched. } \\
\text { Occurs almost exclusively in middle-aged, dark-skinned people. }\end{array}$ \\
\hline $\begin{array}{l}\text { Lichen planus (non-reticular types) } \\
\text { and lichenoid lesions, including } \\
\text { chronic Graft Versus Host Disease }\end{array}$ & $\begin{array}{l}\text { Sometimes associated with typical cutaneous lesions and mucosal lesions } \\
\text { outside the oral cavity. Almost always bilateral presentation } \\
\text { Several clinical subtypes of lichen planus may occur simultaneously } \\
\text { The erosive/ erythematous type and the plaque type may morphologically be } \\
\text { indistinguishable from leukoplakia. } \\
\text { Heavy use of tobacco is in favor of a diagnosis of leukoplakia. } \\
\text { A biopsy is not always diagnostic. }\end{array}$ \\
\hline Lichen sclerosus & $\begin{array}{l}\text { Atrophic, scarlike appearance; often cutaneous involvement as well. Rather } \\
\text { typicical histopathology. }\end{array}$ \\
\hline Linea alba & Clinical diagnosis; almost always bilateral on the line of occlusion \\
\hline Lupus erythematosus & $\begin{array}{l}\text { Almost always cutaneous involvement as well. In such cases the oral lesions } \\
\text { can be diagnosed based on clinical aspects only. }\end{array}$ \\
\hline Morsicatio & $\begin{array}{l}\text { History of habitual chewing or biting. Clinical aspect of irregular whitish- } \\
\text { yellowish flakes, often bilateral, is rather diagnostic. }\end{array}$ \\
\hline $\begin{array}{l}\text { Papilloma and allied lesions, e.g. } \\
\text { condyloma acuminatum, multifocal } \\
\text { epithelial hyperplasia, verruca } \\
\text { vulgaris }\end{array}$ & $\begin{array}{l}\text { Clinical aspect; medical history. A biopsy may be helpful, including HPV } \\
\text { typing }\end{array}$ \\
\hline Skin graft, e.g. after vestibuloplasty & History of a previous graft \\
\hline $\begin{array}{l}\text { Smoker's palate ("stomatitis } \\
\text { nicotina") }\end{array}$ & Usually a clinical diagnosis. \\
\hline Snuff dipper's lesion & See keratotic lesions (tobacco pouch keratosis) \\
\hline $\begin{array}{l}\text { Syphilis, secondary ("mucous } \\
\text { patches") }\end{array}$ & $\begin{array}{l}\text { Medical history; demonstration of T.pallidum; serology. } \\
\text { The clinical presentation may vary from multiple "mucous patches" to less } \\
\text { characteristic whitish lichenoid and leukoplakialike changes of the oral mucosa; } \\
\text { another clinical presentation consists of multiple red lesions on the dorsal } \\
\text { tongue and palate }\end{array}$ \\
\hline
\end{tabular}

lesions is another source of confusion. Some of these lesions, such as reversed smoking keratosis and tobacco pouch keratosis are indisputily potential (pre)malignant and are not always characterized histopathologically by (hyper)keratosis. Admittedly, the risk of malignant transformation in predominantly white lesions of the alveolar ridge ("alveolar ridge keratosis") and the buccal gingiva ("frictional keratosis") is lower than for similar lesions located on the borders of the tongue or the floor of the mouth. It seems questionable, however, to remove such lesions from the category of leukoplakia. Of course, it is well recognized that avoidance of the term leukoplakia for lesions which carry a low risk of malignant transformation is an attractive option with regard to patient information.

The distinction between leukoplakia and non-reticular lichen planus seems to be the biggest challenge in the clinical diagnostic process. Theoretically, these lesions may occur simultaneously or may perhaps transform in time in one another, e.g. lichen planus transforming into leukoplakia.

The recommendation that each leukoplakia should be biopsied may be somewhat questionable at the specialists' level, but seems a safe advise for dentists. 


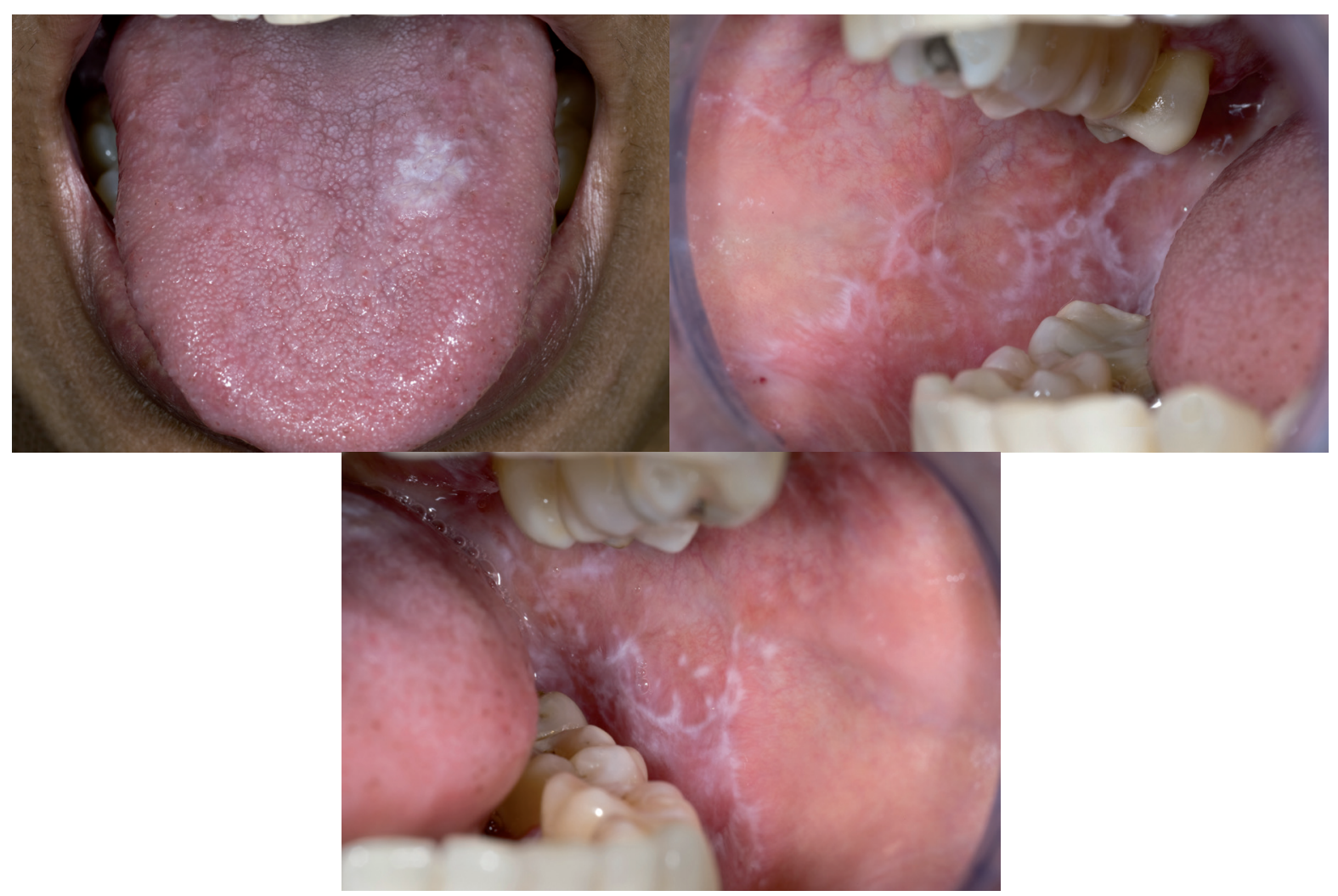

Fig. 1: White lesion at the dorsum of the tongue that clinically qualifies for leukoplakia, plaque type lichen planus and perhaps also for hyperplastic candidiasis (a); only because of the simultaneous presence of lichen planus lesions elsewhere in the oral cavity there is a strong preference to diagnose the lingual lesion as plaque type lichen planus ( $b$ and $c)$.

\section{Recommendation}

In case of a clinical diagnosis of leukoplakia or where such diagnosis is part of the differential diagnosis the dentistgeneral practitioner is advised to look for consultation with a specialist both for confirmation or exclusion of the diagnosis and the further management of the patient. Also patient information about leukoplakia can probably better be provided by a specialist than by a general practitioner who is rarely confronted with this lesion.

\section{References}

1. Lodi G, Franchini R, Warnakulasuriya S, Varoni EM, Sardella A, Kerr AR, et al. Interventions for treating oral leukoplakia to prevent oral cancer. Cochrane Database Syst Rev. 2016;7:CD001829.

2. Warnakulasuriya S, Johnson NW, van der Waal I. Nomenclature and classification of potentially malignant disorders of the oral mucosa. J Oral Pathol Med. 2007;36:575-80.

3. Zegarelli DJ, Silvers DN. Shedding oral mucosa. Cutis. 1994;54:323-6.

4. Schiodt M, Larsen V, Bessermann M. Oral findings in glassblowers. Community Dent Oral Epidemiol. 1980;8:195-200.

5. Natarajan E, Woo SB. Benign alveolar ridge keratosis (oral lichen simplex chronicus): A distinct clinicopathologic entity. J Am Acad Dermatol. 2008;58:151-7.

6. Mignogna MD, Fortuna G, Leuci S, Adamo D, Siano M, Makary

$\mathrm{C}$, et al. Frictional keratoses on the facial attached gingiva are rare clinical findings and do not belong to the category of leukoplakia. J Oral Maxillofac Surg. 2011;69:1367-74.

7. Eversole LR, Eversole GM, Kopcik J. Sanguinaria-associated oral leukoplakia: comparison with other benign and dysplastic leukoplakic lesions. Oral Surg Oral Med Oral Pathol Oral Radiol Endod. 2000;89:455-64.

8. Allen CM, Blozis GG. Oral mucosal reactions to cinnamon-flavored chewing gum. J Am Dent Assoc. 1988;116:664-7.

9. Esteva A, Kuprel B, Novoa RA, Ko J, Swetter SM, Blau HM, et al. Dermatologist-level classification of skin cancer with deep neural networks. Nature. 2017;542:115-8.

\section{Conflict of interest}

None. 